\title{
COMMUNICATION
}

Cite this: DOI: $10.1039 / \times 0 \times x 00000 x$

\section{Borane as an Efficient Directing Group. Stereoselective 1,2-Addition of Organometallic Reagents to Borane P-Stereogenic N- Phosphanylimines.}

\author{
Areli Flores-Gaspar, ${ }^{a}$ Sílvia Orgué, ${ }^{a}$ Arnald Grabulosa, ${ }^{\mathrm{b}}$ Antoni Riera, ${ }^{\text {ac* }}$ Xavier \\ Verdaguer ${ }^{\text {ac* }}$
}

Received 00th January 2012

Accepted 00th January 2012

DOI: $10.1039 / x 0 x x 00000 x$

www.rsc.org/

In non-coordinating solvents, borane was shown to be an efficient directing group for the stereoselective 1,2-addition of organolithium reagents to $\mathbf{P}$-stereogenic $N$-phosphanylimines. Selectivity was reversed in coordinating solvents. This process can lead to novel ligand scaffolds for asymmetric catalysis.

The development of more efficient chiral ligands, especially those containing new chiral skeletons, is a key issue in the field of asymmetric catalysis. ${ }^{1}$ Our group has recently described the synthesis of optically pure borane-protected amino-phosphane $\mathbf{1}$ as a valuable $\mathrm{P}^{*}$-building block for ligand synthesis. ${ }^{2}$ In this regard, the tertbutylmethylphosphane fragment is of particular interest because of the high steric bias provided by the alkyl groups attached to phosphorus. ${ }^{3}$ With the aim to selectively build novel carbon skeletons around aminophosphane 1, we focused on the stereoselective addition of organometallic reagents to type II N-phosphanylimines (Scheme 1).

In this context, Ellman and co-workers reported that the tertbutanesulfinyl group provides excellent stereocontrol upon the addition of Grignard reagents to the corresponding aldimines. ${ }^{4}$ Also, Colobert showed that P-stereogenic $\mathrm{N}$-phosphinoylaldimines undergo 1,2-addition with moderate selectivity (Scheme 2). ${ }^{5}$ In both cases, a six-membered transition state in which the oxygen atom acts as a directing group with coordination to magnesium is invoked to explain the selectivity. Unlike these examples, aldimine II does not bear a directing oxygen group but rather a borane-protecting group. The latter is a desirable feature when the resulting phosphane has to be further used as ligand in metal catalysis; ${ }^{6}$ however, its role as directing group in the 1,2-addition of organometallic reagents is unprecedented? ${ }^{7}$
Here we report that borane is in fact an efficient directing group in the stereoselective 1,2-addition of organolithium reagents to type II aldimines. In addition, we describe the solvent effect encountered in this process and how this reaction selectively leads to novel ligands for asymmetric metal-catalysis.

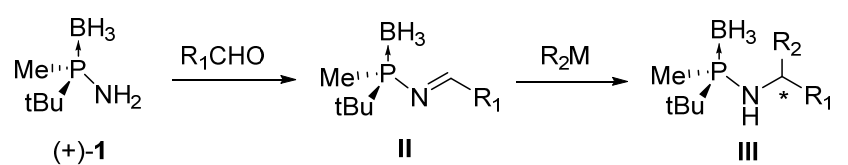

(+)-1

Scheme 1 Borane tert-Butyl methyl aminophosphane 1 and its corresponding aldimine.

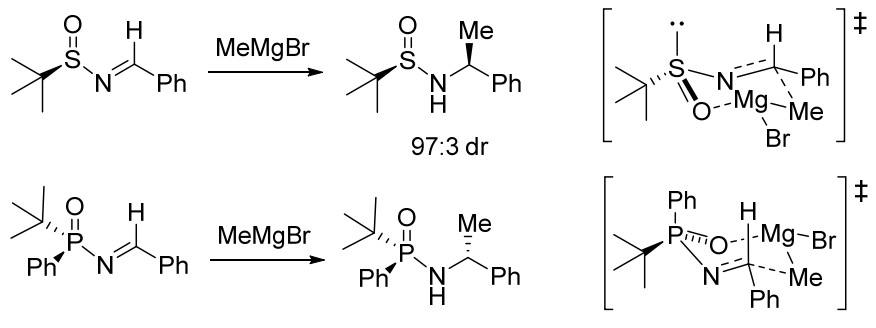

$85: 15 \mathrm{dr}$

Scheme 2 Stereoselective 1,2-additions to sulfinyl and phosphanoyl aldimines.

The synthesis of imines derived from (+)-1 was first attempted unsuccessfully by a condensation reaction with several aldehydes using $\mathrm{Ti}(\mathrm{O} P \mathrm{Pr})_{4}, \mathrm{Ti}(\mathrm{OEt})_{4}$ or $\mathrm{TiCl}_{4}$ as Lewis acid and water scavenger in 
THF or toluene solvent. Finally, microwave-promoted condensation using neat $\mathrm{Ti}(\mathrm{OEt})_{4}$ produced the desired imines in a reproducible manner in moderate yields (Scheme 3). Aldimines 2, $\mathbf{3}$ and $\mathbf{4}$ were obtained as single $E$ isomers, as shown by ${ }^{1} \mathrm{H}$ NMR of the crude reaction mixture and $\mathrm{X}$-ray analysis. ${ }^{8}$ In the ${ }^{1} \mathrm{H}$ NMR spectra, the resulting aldimines showed a sharp $\mathrm{H}-\mathrm{C}=$ resonance between 9.0 and 9.2 ppm, with a $J_{P}$ coupling constant of $26-27 \mathrm{~Hz}$.

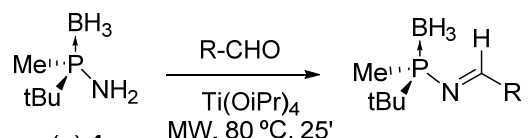

$(+)-1$<smiles>[13CH3][13C]([13CH3])([13CH3])/N=C/c1ccccc1</smiles>

$2(57 \%)$<smiles>[13CH3][13C]([13CH3])([13CH3])/N=C/c1cccs1</smiles>

$3(58 \%)$

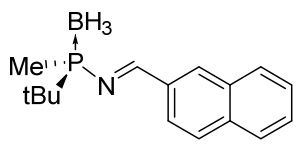

$4(51 \%)$
Scheme 3. Stereoselective 1,2-additions to sulfinyl and phosphanoyl aldimines.

With the optically pure imines in hand, we next studied their reaction with $\mathrm{MeMgBr}$ and MeLi. As a model substrate we took imine 2 (Table 1). Reaction of $\mathbf{2}$ with methylmagnesium bromide in dichloromethane (DCM) did not provide a reaction product, even at room temperature, and starting material was recovered (Table 1, entries 1 and 2). In contrast, the reaction of $\mathbf{2}$ with methyllithium ( 3 equiv.) in DCM at $-78^{\circ} \mathrm{C}$ provided the desired 1,2-addition product in a 98:2 diastereomeric ratio (Table 1, Entry 3). The major diastereomer 5 a showed the relative $S_{\mathrm{P}}, \mathrm{S}$ configuration (vide infra). Increasing the amount of MeLi improved the yield, achieving 95\% (Table 1, entry 4). The use of toluene as solvent slightly reduced the selectivity to $92: 8 \mathrm{dr}$ (Table 1, entry 5). Most remarkably, the use of a coordinating solvent like THF produced an inversion in selectivity (29:71 dr), and the major isomer was now $\mathbf{5 b}$ with the $S_{\mathrm{P}}, R$ configuration (Table 1 , entry 6 ). Reaction in 1,2-dimethoxyethane (DME) or diethylether provided almost a 1:1 mixture of diastereomers (Table 1, entries 7 and 8). Finally, the use of THF with lithium-cation scavengers like 18-crown-16 or TMEDA gave similar results to those achieved with THF alone (Table 1, entries 9 and 10). The present results contrast with those of Ellman and Colobert, who described that the best reagents for the stereoselective addition to sulfinyl and phosphanoyl aldimines were Grignard reagents and that alkyllithium reagents provided low stereoselectivity. ${ }^{4,5}$ The solvent effect observed in the stereochemical outcome of the present system is remarkable. A reversal of the facial selectivity has also been described for the addition of ArLi vs. ArMgX reagents to tert-Butanesulfinyl aldimines, however, the selectivities observed are generally lower. ${ }^{9}$

To assess the scope of the 1,2-addition process, imines 2-4 were treated with various alkyl and aryllithium reagents in DCM and THF solvents (Scheme 4). Addition of MeLi to thiophenyl and naphthylimines $\mathbf{3}$ and $\mathbf{4}$ in DCM took place with excellent yield and produced isomers $\mathbf{6 a}$ and $\mathbf{7 a}$ with $98: 2$ and $97: 3 \mathrm{dr}$ respectively. The

opposite isomers $\mathbf{6} \mathbf{b}$ and $\mathbf{7 b}$ were obtained when the reaction was conducted in THF; however, with lower selectivity (37:67 and 25:75 dr). The solvent effect was even more marked when the imines were reacted with n-BuLi. Addition of n-BuLi to imine $\mathbf{2}$ in DCM yielded 98:2 dr of 8a while in THF a notable 12:88 dr was obtained. In the case of thiophenylimine 3, the selectivity was reversed for compounds $9 \mathbf{a}$ and 9b; 90:10 dr in DCM and 10:90 in THF. Finally, addition of phenyllithium was the most $\left(S_{p}, S\right)$-selective of all the 1,2-additions studied. Thus, when the reaction was run in DCM, compounds 10a and 11a were obtained basically as pure diastereomers, as determined by ${ }^{1} \mathrm{H}$ NMR spectroscopy. However, in THF, the selectivity was almost 1:1 and the inversion of selectivity was not observed.

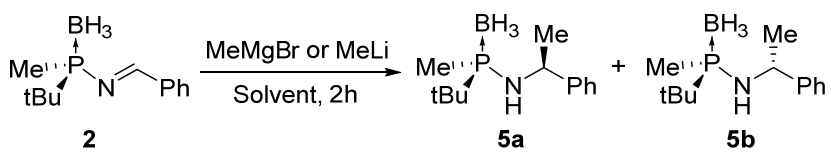

Table 1. Solvent-dependent 1,2-addition of organometallic reagents to 2 .

\begin{tabular}{|c|c|c|c|c|}
\hline Entry & Reagent & Solvent & $\begin{array}{l}\text { Yield } \\
(\%)^{\mathrm{a}}\end{array}$ & $\begin{array}{c}d r^{b} \\
(5 a / 5 b)\end{array}$ \\
\hline 1 & MeMgBr (3eq.) ${ }^{c}$ & DCM & NR & - \\
\hline 2 & $\operatorname{MeMgBr}(3 \text { eq. })^{d}$ & DCM & NR & - \\
\hline 3 & MeLi (3 eq.) $)^{c}$ & DCM & 88 & $98: 2$ \\
\hline 4 & $\operatorname{MeLi}(5 \text { eq. })^{c}$ & DCM & 95 & $98: 2$ \\
\hline 5 & MeLi (5 eq.) ${ }^{c}$ & Toluene & 97 & $92: 8$ \\
\hline 6 & $\operatorname{MeLi}(5 \text { eq. })^{c}$ & THF & 90 & 29:71 \\
\hline 7 & $\operatorname{MeLi}(5 \text { eq. })^{c}$ & 1,2-DME & 82 & 41:59 \\
\hline 8 & $\operatorname{MeLi}\left(5\right.$ eq.) ${ }^{c}$ & $\mathrm{Et}_{2} \mathrm{O}$ & 63 & $43: 57$ \\
\hline 9 & MeLi (5 eq.) $)^{c}$ & THF/18-crown-6 & 85 & $27: 73$ \\
\hline 10 & $\operatorname{MeLi}(5 \text { eq. })^{c}$ & THF/TMEDA & 90 & $32: 68$ \\
\hline
\end{tabular}

a) Yields refer to an isolated mixture of diastereomers. b) Determined by ${ }^{1} \mathrm{H}$ NMR of crude mixtures. ${ }^{\text {c) }}$ Reaction run at $-78^{\circ} \mathrm{C}$. ${ }^{\text {d) }}$ Reaction run at room temperature.

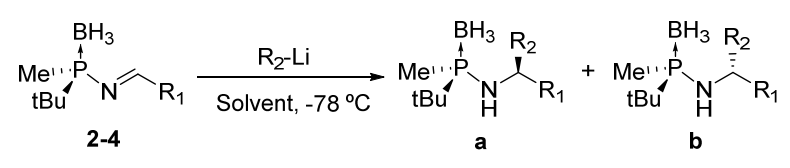

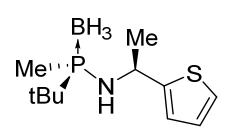

$6 a, 6 b$

DCM: $86 \%, 98: 2 \mathrm{dr}$ THF: $83 \%, 37: 63 \mathrm{dr}$

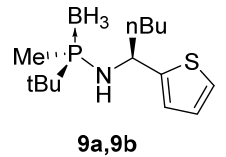

DCM: $91 \%, 90: 10 \mathrm{dr}$ THF: $97 \%, 10: 90 \mathrm{dr}$

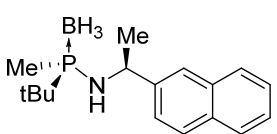

$7 a, 7 b$

DCM: $99 \%, 97: 3 \mathrm{dr}$ THF: $99 \%, 25: 75 \mathrm{dr}$
DCM: $99 \%,>99: 1 \mathrm{dr}$ THF: $93 \%, 60: 40 \mathrm{dr}$

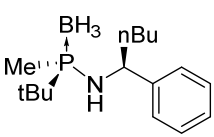

$8 \mathrm{a}, \mathbf{8 b}$

DCM: $92 \%, 98: 2 \mathrm{dr}$ THF: $89 \%, 12: 88 \mathrm{dr}$
Scheme 4. 1,2-Addition of organometallic reagents to imines 2, 3 and 4 with several R-Li reagents.

To demonstrate the utility of this process for the synthesis of chiral ligands for coordination chemistry and catalysis, compound 10a was deprotected and coordinated to iridium (Scheme 5). For this purpose, 
optically pure aminophosphane $\left(R_{\mathrm{p}}, R\right)-\mathbf{1 0 a}$ was treated with diazabicyclo[2.2.2]octane (DABCO) in toluene at $100^{\circ} \mathrm{C}$ and subsequently reacted with $[\operatorname{Ir}(\operatorname{cod}) \mathrm{Cl}]_{2}$ to produce the chloro-iridium complex 12 in 63\% yield. Chloride abstraction of 12 with NaBArF led to the cationic Ir-complex 13 (61\%), in which the thiophene sulfur atom is chelated to the metal center. Single crystals of $\mathbf{1 3}$ suitable for $\mathrm{X}$-ray analysis were obtained by hexane/DCM layering. The solved crystal structure of $\mathbf{1 3}$ is depicted in Figure 1. The X-ray structure of $\mathbf{1 3}$ allowed us to confirm that the relative stereochemistry obtained for the 1,2-addition of organolithium reagents to type II aldimines is $\left(S_{P}, S\right) /\left(R_{P}, R\right)$ when DCM is used as solvent.

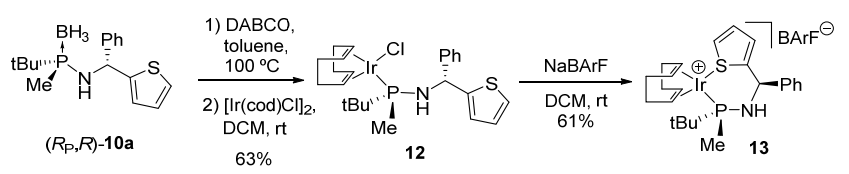

Scheme 5. Synthesis of a cationic iridium complex from compound $(R, R)-9$ a.

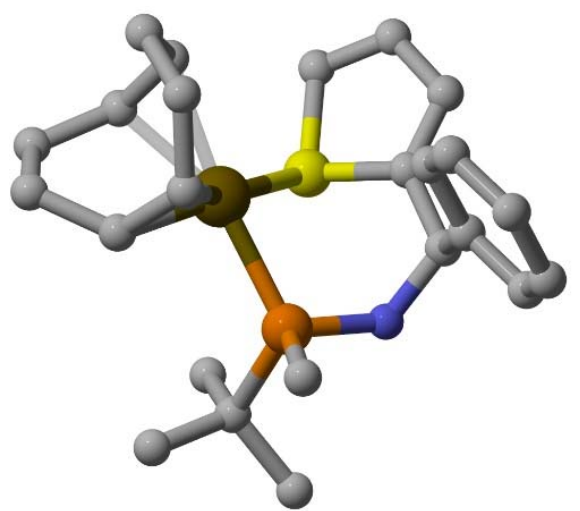

Figure 1. X-ray structure of Ir-complex 13. Inclusion $\mathrm{CH}_{2} \mathrm{Cl}_{2}$ molecule and $\mathrm{BArF}$ counterion are omitted for clarity. Selected distances (Å) and angles: P-Ir 2.295, S-Ir 2.356, P-Ir-S 86.3‥

The stereochemical outcome of the 1,2-addition of organolithium reagents to P-stereogenic borane-aldimines in non-coordinated solvents like DCM is consistent with a cyclic transition state in which the $\mathrm{BH}_{3}$ group acts as directing group by coordination to lithium (Figure 2). This implies a distorted chair-like transition state in which the borane group is coordinated in a $\eta^{2}$ binding mode to lithium. $\mathrm{BH}_{3-}$ $\mathrm{Li}$ interactions are known both in the solid state and in solution. ${ }^{10}$ The typical $\mathrm{Li} \cdots \mathrm{B}$ distance in $\eta^{2}-\mathrm{BH}_{\mathrm{n}}-\mathrm{Li}$ contacts is around $2.38-2.47 \AA^{11}$ which is considerably longer than that found in $\mathrm{S}=\mathrm{O} \cdots \mathrm{Li}\left(1.83-1.93 \AA \mathrm{A}^{12}\right.$ and $\mathrm{P}=\mathrm{O} \cdots \mathrm{Li}\left(1.83-1.91 \AA \mathrm{A}^{13}\right.$ contacts. However, the longer distance between the directing group and the attacking organometallic reagent does not imply a reduction in selectivity.

The reversed selectivity observed in coordinating solvents like THF may be explained by the disruption of the chelated transition state due to solvent coordination to Li and the attack of the R-Li reagent to the less hindered face of the $E$-imine (Figure 2). The lone pair of the imine will be positioned anti to the negatively charged $\mathrm{BH}_{3}$ group to avoid electronic repulsion. ${ }^{14}$ In this conformation, since the pro-S face of the imine is blocked by the bulky tert-butyl group, the attack of the organolithium reagent takes place preferably at the pro- $\mathrm{R}$ face, thus leading to the $S_{P}, R$ diastereomer.

Non-coordinating solvent (DCM)

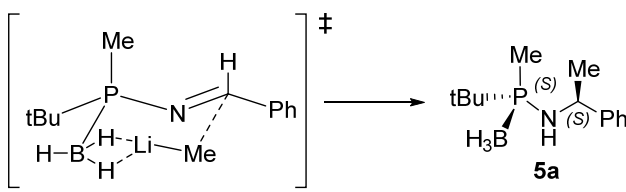

Coordinating solvent (THF)

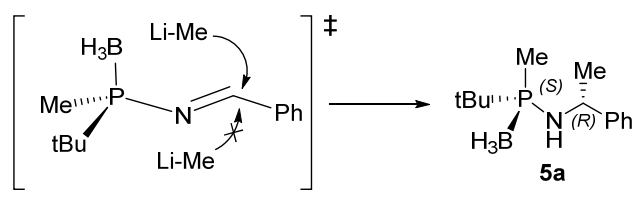

Figure 2. Mechanistic proposal.

In summary, we have shown that the 1,2-addition of organolithium reagents to borane $\mathrm{P}$-stereogenic $\mathrm{N}$-phosphanylimines is a highly stereoselective process. In non-coordinating solvents, the $\mathrm{BH}_{3}$ moiety proved to be an effective directing group that binds to the $\mathrm{Li}$ atom in a chair-like cyclic transition state, leading to selectivities up to >99:1 dr. In coordinating solvents like THF, a remarkable reversal of the selectivity was observed. Finally, we have demonstrated that the present methodology has the capacity to produce novel chiral ligands for coordination chemistry and catalysis. The results in this area will be reported in due time.

We thank the Spanish Ministerio de Economia y Competitividad (CTQ2011-23620), the Generalitat de Catalunya (2014SGR-234, and IRB Barcelona for financial support. A.F.-G. thanks the CONACYT for a postdoctoral fellowship. S.O. thanks the Generalitat de Catalunya for FI fellowship.

\section{Notes and references}

${ }^{a}$ Institute for Research in Biomedicine (IRB Barcelona), c/ Baldiri Reixac 10, E-08028, Spain. Fax: (+34) 934037095, phone : (+34) 934034813, Email: antoni.riera@irbbarcelona.org, xavier.verdaguer@irbbarcelona.org.

${ }^{b}$ Departament de Química Inorgànica, Universitat de Barcelona, Martí i Franquès 1, E-08028 Barcelona, Spain.

c Departament de Química Orgànica, Universitat de Barcelona, Martí i Franquès 1, E-08028 Barcelona, Spain.

† Electronic Supplementary Information (ESI) available: Experimental procedures, characterization data and NMR spectra for new compounds; crystallographic data file in cif format (CCDC 1032194 and 1037633). See DOI: $10.1039 / \mathrm{c} 000000 \mathrm{x} /$

1 A. Börner, Ed., Phosphorous Ligands in Asymmetric Catalysis, WileyWCH, Weinheim, 2008, vol. I-III.

2 (a) M. Revés, C. Ferrer, T. León, S. Doran, P. Etayo, A. Vidal-Ferran, A. Riera, and X. Verdaguer, Angew. Chem. Int. Ed., 2010, 49, 94529455. (b) T. León, A. Riera, and X. Verdaguer, J. Am. Chem. Soc., 2011, 133, 5740-5743. (c) T. León, M. Parera, A. Roglans, A. Riera, and X. Verdaguer, Angew. Chem. Int. Ed., 2012, 51, 6951-6955. (d) E. Cristóbal-Lecina, P. Etayo, S. Doran, M. Revés, P. Martín-Gago, A. 
Grabulosa, A. R. Costantino, A. Vidal-Ferran, A. Riera, and X. Verdaguer, Adv. Synth. Catal. 2014, 356, 795-804.

3 (a) T. Imamoto, J. Watanabe, Y. Wada, H. Masuda, H. Yamada, H. Tsuruta, S. Matsukawa, and K. Yamaguchi, J. Am. Chem. Soc., 1998, 120, 1635-1636. (b) T. Imamoto, K. Sugita, and K. Yoshida, J. Am. Chem. Soc., 2005, 127, 11934-11935. (c) T. Imamoto, K. Tamura, Z. Zhang, Y. Horiuchi, M. Sugiya, K. Yoshida, A. Yanagisawa, and I. D. Gridnev, J. Am. Chem. Soc., 2012, 134, 1754-1769. (d) W. Tang, A. G. Capacci, A. White, S. Ma, S. Rodriguez, B. Qu, J. Savoie, N. D. Patel, X. Wei, N. Haddad, N. Grinberg, N. K. Yee, D. Krishnamurthy, and C. H. Senanayake, Org. Lett., 2010, 12, 1104-1107.

4 (a) G. Liu, D. A. Cogan, and J. A. Ellman, J. Am. Chem. Soc., 1997, 119, 9913-9914. (b) D. A. Cogan, G. Liu, and J. A. Ellman, Tetrahedron, 1999, 55, 8883-8904. (c) M. T. Robak, M. A. Herbage, and J. A. Ellman, Chem. Rev., 2010, 110, 3600-3740.

5 (a) I. N. Francesco, A. Wagner, and F. Colobert, Chem. Commun. 2010, 46, 2139-2141. (b) I. Notar Francesco, C. Egloff, A. Wagner, and F. Colobert, Eur. J. Org. Chem., 2011, 4037-4045.

6 N. V Andrushko and A. Börner, in Phosphorus Ligands in Asymmetric Catalysis, ed. A. Börner, Weinheim, 2008, pp. 1275-1347.

7 The $\mathrm{BH}_{3}$ group has been used for the directed $\alpha$-lithiation of aminoboranes and phosphine-borane compounds, see: a) X.-M. Sun, K. Manabe, W. W.-L. Lam, N. Shiraishi, J. Kobayashi, M. Shiro, H. Utsumi, and S. Kobayashi, Chem. Eur. J., 2004, 11, 361-368. b) A. Ariffin, A. J. Blake, M. R. Ebden, W.-S. Li, N. S. Simpkins, and D. N. A. Fox, J. Chem. Soc. Perkin Trans. 1, 1999, 2439-2447. c) E. Vedejs and J. T. Kendall, J. Am. Chem. Soc., 1997, 119, 6941-6942. d) G. Hoge, J. Am. Chem. Soc., 2003, 125, 10219-27.

8 See the Electronic supplementary information for the X-ray structure of aldimine $\left(R_{\mathrm{P}}\right)-(-)-2$.

9 N. Plobeck and D. Powell, Tetrahedron: Asymmetry, 2002, 13, 303310.

10 (a) G. Barozzino Consiglio, P. Queval, A. Harrison-Marchand, A. Mordini, J.-F. Lohier, O. Delacroix, A.-C. Gaumont, H. Gérard, J. Maddaluno, and H. Oulyadi, J. Am. Chem. Soc., 2011, 133, 64726480. (b) K. Izod, C. Wills, W. Clegg, and R. W. Harrington, Organometallics, 2010, 29, 4774-4777. (c) G. Müller and J. Brand, Organometallics, 2003, 22, 1463-1467.

11 (a) J. Langer, K. Wimmer, H. Görls, and M. Westerhausen, Dalton Trans., 2009, 2951-2957. (b) K. Izod, C. Wills, W. Clegg, and R. W. Harrington, Organometallics, 2010, 29, 4774-4777.

12 (a) C. Lambert, F. Hampel, and P. von Ragué Schleyer, J. Organomet. Chem., 1993, 455, 29-35. (b) J. M. Butler and G. M. Gray, J. Chem. Crystallogr., 2003, 33, 557-562.

13 (a) R. A. Kresinski and J. P. Fackler Jnr, Acta Crystallogr. Sect. C Cryst. Struct. Commun., 1993, 49, 1059-1061. (b) M. M. Meinholz and D. Stalke, Z. Anorg. Allg. Chem. 2011, 637, 2233-2238. (c) J. P. Fackler, C. A. López, and R. E. P. Winpenny, Acta Crystallogr. Sect. C Cryst. Struct. Commun. 1992, 48, 2218-2220.

14 This conformation is also the one displayed in solid state. See the $\mathrm{X}$ ray structure of compound $\left(R_{\mathrm{P}}\right)-(-)-2$ in the Electronic supplementary information. 